\title{
PENGENALAN E-COMMERCE PADA PENGERAJIN TANGAN DI DESA SAMBIRENTENG KECAMATAN TEJAKULA KABUPATEN BULELENG
}

\author{
I. M. S. Putra' ${ }^{1}$ I. M. S. Raharja ${ }^{2}$, N. P. Sutramiani ${ }^{3}$, A. A. N. H. Susila ${ }^{4}$
}

\begin{abstract}
ABSTRAK
Kerajinan Tangan adalah menciptakan suatu produk atau barang yang dilakukan oleh tangan dan memiliki fungsi pakai atau keindahan sehingga memiliki nilai jual. Banyak industri rumah tangga menggunakan komoditas kerajinan tangan sebagai sumber ekonominya. Desa Sambirenteng, Kecamatan Tejakula, Kabupaten Buleleng selain sebagai petani, sebagian penduduknya dari segi ekonomi mengandalkan industri rumah tangga dari kerajinan tangan olahan lidi daun kelapa atau lidi daun lontar yaitu piring ingke. Proses penjualan produk jadi selama ini masih dilakukan dengan cara konvensional, yaitu dengan menunggu order dari konsumen atau pedagang pasar secara langsung tanpa melalui teknologi komunikasi yang berkembang saat ini. Kegiatan pengabdian kepada masyarakat ini ditujukan untuk para pengerajin piring ingke di Desa Sambirenteng agar bisa mulai mempromosikan produk kerajinan tangannya menggunakan media promosi online yang sudah disediakan, sehingga diharapkan promosi dan penjualan produk jadi semakin meningkat. Kegiatan ini meliputi, pengarahan, pemberian, pelatihan penggunaan dan pendampingan promosi melalui media online kepada pelaku industri rumah tangga.
\end{abstract}

Kata kunci : kerajinan tangan, pengerajin, ingke, penjualan, online

\begin{abstract}
Handicrafts are creating products or goods that are done by hand and have the function of wearing or making the beauty selling value. Many home industries use handicraft as their economic source. Sambirenteng Village, Tejakula Subdistrict, Buleleng Regency. Apart from being a farmer, most of the population is economically dependent on the home industry from handicrafts made from palm leaf sticks or papyrus leaf sticks, namely Ingke plates. The process of selling finished products has so far been carried out conventionally, that is by waiting for orders from consumers or market traders directly without going through the communication technology developed at this time. This community service activity is aimed at the craftsmen of Ingke dishes in Sambirenteng Village to start promoting handicraft products supported by online promotion media that have been provided. So that it is expected that promotion and sales of finished products will increase. This activity includes briefing, giving training, and promotion assistance through online media for home industry assistance.
\end{abstract}

Keywords: handicrafts, craftsmen, ingke, sales, online

\footnotetext{
${ }^{1}$ Program Studi Teknologi Informasi, Fakultas Teknik, Universitas Udayana, Jl. Kampus Bukit Jimbaran, Indonesia, putrasuwija@unud.ac.id

${ }^{2}$ Program Studi Teknologi Informasi, Fakultas Teknik, Universitas Udayana, Jl. Kampus Bukit Jimbaran, Indonesia, sunia.raharja@gmail.com

${ }_{3}^{3}$ Program Studi Teknologi Informasi, Fakultas Teknik, Universitas Udayana, Jl. Kampus Bukit Jimbaran, Indonesia, sutramiani@unud.ac.id

${ }^{4}$ Program Studi Teknologi Informasi, Fakultas Teknik, Universitas Udayana, Jl. Kampus Bukit Jimbaran, Indonesia, harysusila@unud.ac.id
} 


\section{PENDAHULUAN}

Perkembangan pasar industri kreatif kini sudah semakin berkembang dibarengi dengan perkembangan teknologi yang bisa membantu untuk memasarkan produk dari industri kreatif rumah tangga. Ekonomi kreatif yang identik dengan industri kreatif, pada saat ini dianggap dapat memberikan kontribusi yang sangat signifikan, bagi perekonomian daerah (Nurchayati \& Ratnawati, 2016). Pendapat tersebut, didukung dengan pendapat (Perdagangan Republik Indonesia, 2008), mencatat bahwa kontribusi industry kreatif terhadap PDB di tahun 2002 hingga 2006 ratarata mencapai 6,3\% atau setara dengan 152,5 trilyun jika dirupiahkan dan meningkat menjadi 7,6 $\%$.di tahun 2009 (Pusat Komunikasi Publik, 2011). Industri kreatif sanggup menyerap tenaga kerja hingga 5,4juta dengan tingkat partisipasi 5,8\%. Saat ini sudah banyak anak muda atau ibu rumah tangga sekalipun yang bisa memanfaatkan waktu kosong untuk menjalankan industri kreatif rumah tangga. Selain menguntungkan menjalankan bisnis kreatif merupakan peluang bisnis yang sangat menjanjikan. Pemasaran dan promosi produk industri kreatif sangat penting, terlebih lagi di era globalisasi yang sudah menggunakan teknologi informasi sebagai sarana penunjang untuk menyebarluaskan informasi produk kepada pelanggan seperti media sosial dan market place online. Hal ini bertujuan untuk memberikan akses kemudahan informasi bagi pembeli untuk melihat produk yang ingin dicarinya (Kreatif:,2015). Sambirenteng adalah sebuah desa di Kecamatan Tejakula, Kabupaten Buleleng, Bali, Indonesia. Desa Sambirenteng terdiri dari beberapa banjar diantaranya: Banjar Geretek, Benben, Sambirenteng,dan Silagading. Sebagian besar penduduk di Desa Sambirenteng adalah petani kebun. Meskipun tidak ada perkebunan yang berskala besar. Mata pencarian lain juga ada berpenghasilan dari industri rumah tangga kerajinan tangan seperti kerajinan piring ingke. Industri kreatif ini bisa menjadi penggerak sektor wisata dan memberikan pencitraan 8

wilayah ke nasional dan internasional sebagai desain penghasil piring ingke sehingga lebih dikenal oleh masyarakat luas (Barringer, 2004). Terlebih lagi sektor pariwisata ini sudah didukung dengan infrastruktur pariwisata seperti penginapan yang sudah mulai dibangun tinggal bagaimana membangkitkan sector ekonomi industri kreatif yang dihasilkan oleh rumah tangga sebagai citra produk khas untuk cindramata wisatawan dan sebagai komiditi pasar daerah. Oleh karena itu kegiatan pengabdian kepada masyarakat yang akan kita lakukan meliputi pengarahan, pemberian, pelatihan penggunaan dan pendampingan promosi melalui media online seperti market place dan media sosial kepada pelaku industry rumah tangga yang ada di Desa Sambirenteng guna memberikan dampak positif berupa peningkatan promosi dan penjualan produk hasil kerajinan tangan.

Beberapa analisis situasi yang dijadikan dasar pelaksanaan pengabdian ini adalah:

a. Desa Sambirenteng memiliki karakteristik tanah yang tandus karenaberbatasan dengan laut di bag ian utara dan berbatasan dengan perbukitan di bagian selatan sehingga mata pencarian dengan cara bertani menjadi kurang maksimal dari segi penghasilan, oleh karena itu dengan adanya pengabdian ini diharapkan alternatif penghasilan dari industri kerajinan tangan piring ingke menjadi meningkat.

b. Penduduk Desa Sambirenteng sebagian besar terutama generasi muda hijrah ke Denpasar atau kota-kota lain untuk mencari nafkah, dikarenakan minimnya mata pencarian yang menghasilkan penghasilan yang cukup oleh karena potensi kearifan lokal desa yang kurang mendapat perhatian serta sentuhan teknologi sehingga kurang minatnya pemuda untuk mencari mata pencarian di desanya sendiri. Hal ini mengakibatkan Desa Sambirenteng menjadi desa yang cukup sepi dan kurang dikenal di masyarakat umum. 

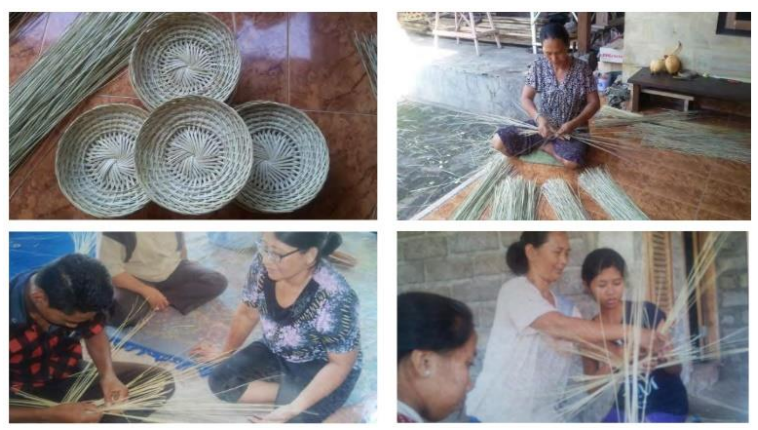

Gambar 1.1 Hasil dan kegiatan proses pembuatan industri rumah tangga kerajinan tangan piring ingke

c. Industri rumah tangga kerajinan tangan piring ingke yang masih menjadi andalan beberapa warga di Desa Sambirenteng, dirasakan oleh warga masih kurang dalam hal promosi dan volume penjualan, karena kurangnya 9

d. media promosi dan penjualan masih dilakukan secara konvensional. Warga juga banyak berharap adanya sarana dan pelatihan khusus cara penggunaan media online yang bisa dipakai untuk mempromosikan produknya tersebut.

\section{METODE PELAKSANAAN}

\subsection{Tujuan Kegiatan}

Tujuan kegiatan ini adalah :

a. Merancang pengembangan industri rumah tangga kerajinan tangan khas Bali.

b. Merumuskan proses bisnis industri rumah tangga kerajinan khas Bali dengan memanfaatkan teknologi informasi.

c. Membantu para pelaku usaha industri rumah tangga kerajinan khas Bali dengan memanfaatkan teknologi informasi.

d. Ikut serta memperkuat industri rumah tangga kerajinan khas Bali melalui pemanfaatan teknologi informasi.

\subsection{Manfaat Kegiatan}

Manfaat kegiatan ini adalah :

a. Mempermudah dan mempercepat proses bisnis industri rumah tangga kerajinan khas Bali.

b. Pengelolaan sumber daya pengusaha industri rumah tangga kerajinan khas Bali menjadi lebih baik.

c. Pengusaha industri rumah tangga kerajinan khas Bali dapat menggunakan teknologi informasi untuk menjalankan bisnisnya

\subsection{Pemecahan Masalah}

Model pemecahan masalah yang digunakan meliputi :

a. Mengembangkan teknologi informasi untuk industri rumah tangga kerajinan khas Bali.

b. Memberikan pelatihan kepada pengusaha industri kerajinan khas Bali berkaitan dengan pemanfaatan teknologi informasi.

c. Memberikan pelatihan kepada pelanggan industri kerajinan khas Bali dalam menggunakan layanan berbasis teknologi informasi. 


\subsection{Metode Kegiatan}

Metode kegiatan yang dilakukan antara lain:

a. Survei ke Desa Sambirenteng untuk analisa kebutuhan dalam pembuatan sarana media online untuk promosi dan penjualan produk kerajinan tangan

b. Merancang media online market place untuk promosi dan penjualan produk

c. Pelatihan dan pendampingan kepada pelaku industri rumah tangga dalam hal penggunaan sarana media online yang telah

\section{HASIL DAN PEMBAHASAN}

Hasil yang diperoleh dari pelaksanaan pengabdian kepada masyarakat di Desa Sambireteng sesuai dengan metode pelaksanaan yang telah ditentukan adalah sebagai berikut :

a. Tim Pengabdi melakukan survey lapangan ke Desa Sambirenteng yang dilaksanakan pada tanggal 29 Juni 2019 untuk melaksanakan kegiatan analisa kebutuhan pembuatan sarana media online untuk promosi dan penjualan produk kerajinan tangan ingke. Survey ini diterima langsung oleh pemilik usaha dan karyawan.
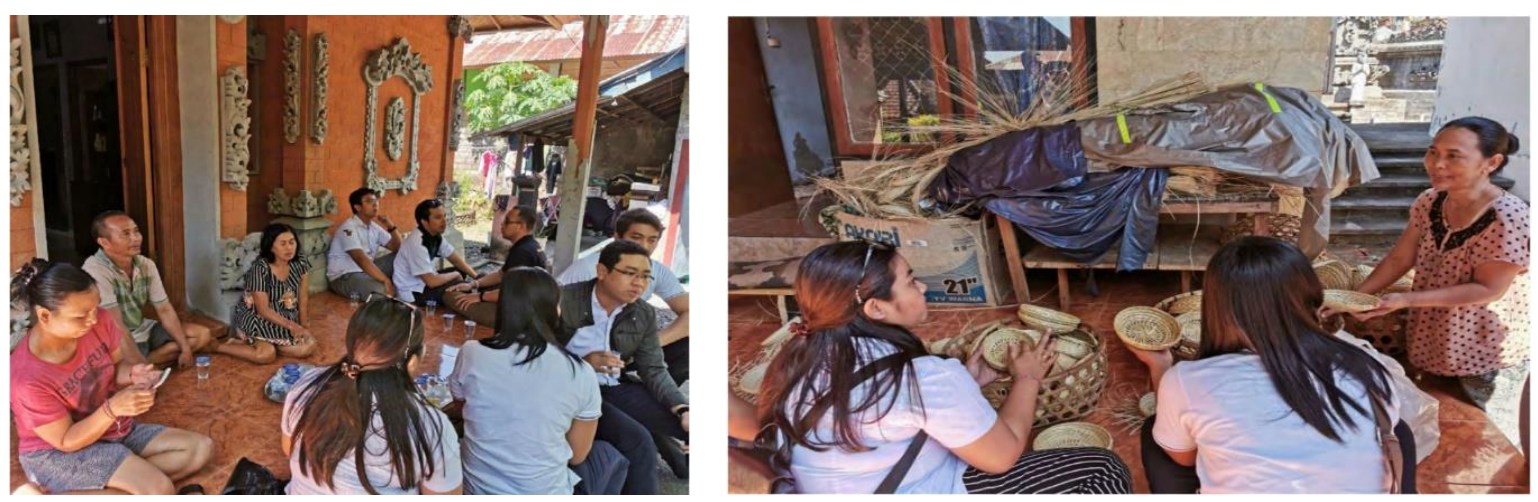

Gambar 3.1. Acara Survey Lapangan dan Wawancara Tim Pengabdian di tempat Usaha Kerajinan Tangan Ingke

b. Berdasarkan hasil survey lapangan dan wawancara pemilik usaha ke Desa Sambirenteng maka Tim Pengabdian mendapatkan data kebutuhan untuk merancang media online ecommerce dan Google Bisnisku untuk promosi dan penjualan produk kerajinan tangan ingke. Berikut perancangan media online ecommerce dan Google Bisnisku.

1. Media Online E-Commerce

Perancangan media online e-commerce penjualan produk kerajinan tangan Ingke di Desa Sambirenteng.

2. Google Bisnisku

Perancangan media online Google Bisnisku untuk promosi produk kerajinan tangan ingke di Desa Sambirenteng. 
c. Media online e-commerce dan Google Bisnisku yang telah dirancang dan dibuat selanjutnya Tim Pengabdian memberikan pelatihan dan pendampingan. Pelatihan dan pendampingan kepada pemilik usaha kerajinan tangan ingke di Desa Sambirenteng dilaksanakan pada tanggal 6 Juli 2019. Tujuan pelatihan dan pendampingan ini agar pemilik usaha mampu menggunakan media online tersebut untuk promosi dan penjualan online.
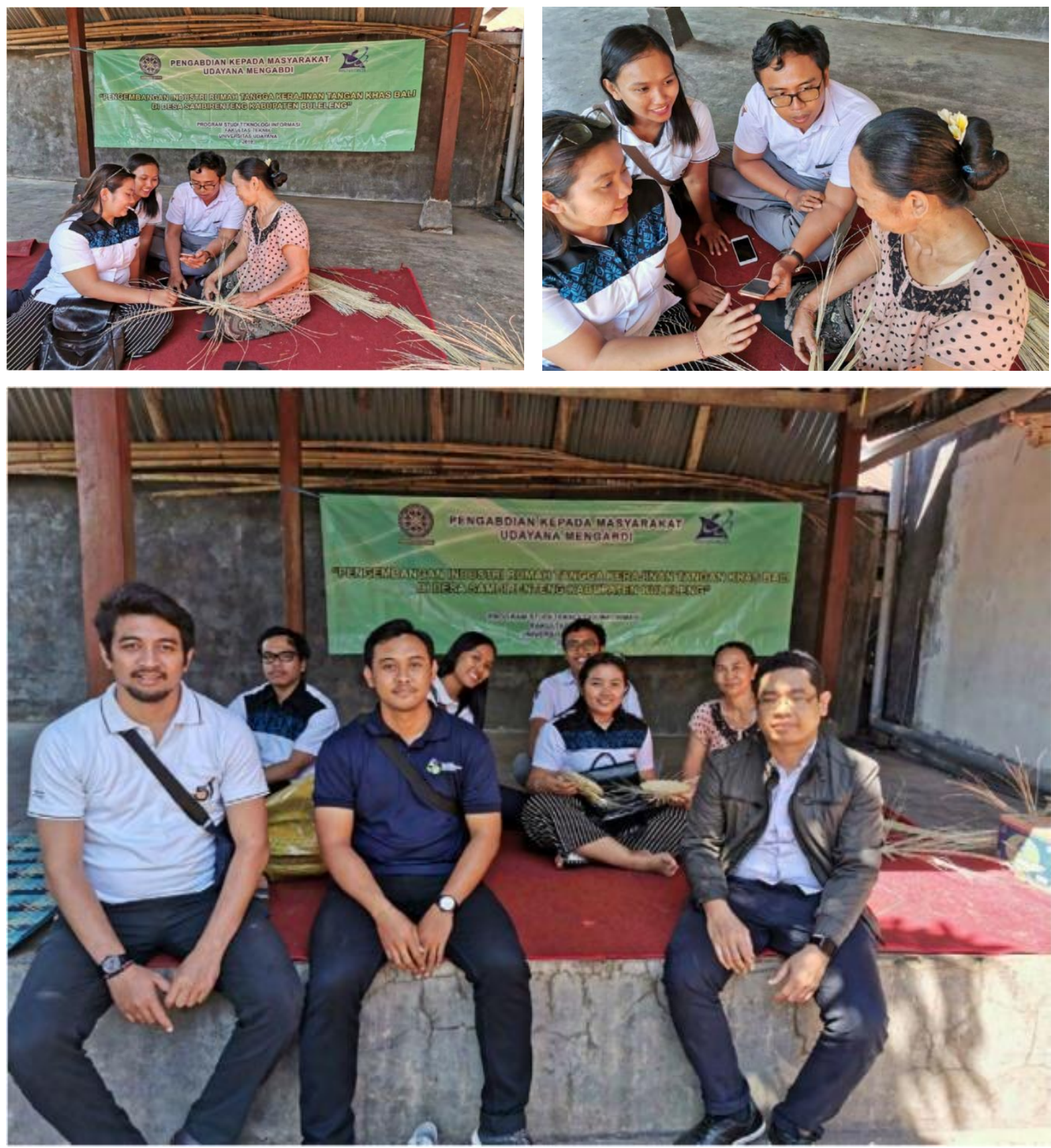

Gambar 3.2 Kegiatan Tim Pengabdian Memberikan Pelatihan dan Pendampingan Media Online

Luaran yang dicapai dari kegiatan pengabdian kepada masyarakat ini adalah : 
a. Pemilik usaha kerajinan tangan ingke di Desa Sambirenteng mampu memahami dan menggunakan media online e-commerce dan Google Bisnisku untuk memasarkan serta menjual produk hasil kerajinan tangan yang ada di Desa Sambirenteng.

b. Pemilik usaha kerajinan tangan ingke di Desa Sambirenteng mampu memahami dan menggunakan media internet, media digital atau media sosial untuk kegiatan pemasaran produk yang lebih efektif dan efisien.

\section{KESIMPULAN}

Berdasarkan hasil dari analisa kebutuhan, pengolahan data, informasi yang didapatkan dari hasil wawancara maupun survai ke pengerajin ingke di Desa Sambirenteng, Kecamatan Tejakula, Kabupaten Buleleng. Dapat disimpulkan bahwa promosi hasil kerajinan tangan ingke di Desa Sambirenteng saat ini membutuhkan media teknologi informasi guna menyebarluaskan informasi hasil produk, dimana segementasi customer yang selama ini customer hanya berasal dari wilayah sekitar desa. Teknologi informasi Digital Marketing yang diperlukan dan mudah untuk dipergunakan oleh pengerajin yang bisa diakses langsung dari smartphone adalah adalah Google Bisnisku dan Free E Commerce. Pelatihan penggunaan Google Bisnisku dan Free E-Commerce sudah dilakukan dengan pengerajin ingke sebagai penggunanya. Kegiatan pengabdian ini mendapatkan apresiasi positif dari pengerajin, karena dapat membantu menyebarluaskan informasi produk kerajinan tangan ingke milik pengerajin.

\section{UCAPAN TERIMA KASIH}

Tim pelaksana mengucapkan terima kasih yang setinggi-tingginya kepada Kementerian Riset, Teknologi dan Pendidikan Tinggi, Rektor Universitas Udayana, Ketua Lembaga Penelitian dan Pengabdian Masyarakat (LPPM) Universitas Udayana dan Fakultas Teknik Universitas Udayana atas dukungan pendanaan kegiatan melalui program pengabdian dengan skim Pengabdian Udayana Mengabdi(PUM) serta pengrajin Ingke di Desa Sambirenteng, Kec. Tejakula, Kab. Buleleng.

\section{DAFTAR PUSTAKA}

Departemen Perdagangan Republik Indonesia (2008). "Pengembangan Ekonomi Kreatif Indonesia 2025: Rencana Pengembangan Ekonomi Kreatif Indonesia 2009-2025"

Barringer, R. (2004). The Creative Economy in Maine: Measurement \& Analysis. The Southern Maine Review, University of Southern Maine.

Kreatif:, T. S. dan K. P. E. (2015). Ekonomi Kreatif: Rencana Pengembangan Teknologi Informasi Nasional 2015-2019 (Cetakan Pe). Jakarta: PT. Republik Solusi.

Nurchayati, \& Ratnawati, A. T. (2016). Strategi Pengembangan Industri Kreatif Sebagai Penggerak Destinasi Pariwisata Di Kabupaten Semarang. Prosiding

Seminar Nasional Multi Disiplin Ilmu \& Call for Papers Unisbank (Sendi_U), 2, 810-819.

Perdagangan Republik Indonesia, D. (2008). Pengembangan Ekonomi Kreatif Indonesia 2025 : Rencana Pengembangan Ekonomi Kreatif Indonesia 2009 - 2025.

Pusat Komunikasi Publik, K. P. (2011). Industri Kreatif Punya Potensi Besar Menopang Ekonomi Nasional (Kina, Karya Indonesia)-Media Ekuitas Produk Indonesia.

https://id.wikipedia.org/wiki/Sambirenteng,_Tejakula,_Buleleng, diakses pada tanggal 14 Februari 2019

https://trendindonesia.com/industri-kreatif-untuk-ibu-rumah-tangga/, diakses pada tanggal 14 Februari 2019 